\title{
四面体マッチング法によるスカラボリュームデータの類似度算定
}

\author{
酒井 晃二0 (京都大学), 南 智規 (京都大学), 小山田 耕二 (京都大学)
}

\section{Tetrahedron matching method for detecting scalar volume similarity}

\author{
Koji SAKAI, Tomoki MINAMI and Koji KOYAMADA
}

\begin{abstract}
Traditional classifying and searching systems have required special features of data from manual input. To overcome this undesirable task, a method which automatically creates and utilizes a "Critical Point Graph (CPG)" as an index of volume data has been proposed. In order to achieve suitable search and classification results, it is required to automatically calculate similarity between CPGs from a set of selected volume data. We introduce a new feature-matching algorithm to make an exact correspondence of positions between two CPGs. This is an extension of "Triangular Matching Algorithm" which is usually employed in the field of 2D fingerprint matching. In order to evaluate the effectiveness, we evaluated the influence of data resolution and arrangement in our proposed CPG based method. We confirmed the effectiveness and usefulness of our proposed CPG based method when applied to numerically constructed weather volume data sets. From computational experiments, our new CPG method has shown suitable ability for similarity calculation between two dissimilar volume data.
\end{abstract}

Keywords: Tetrahedron Matching, Similarity, Volume data

\section{1. はじめに}

一般に,膨大な数值デ一タから新たな知見を得るため には、ニーズに合わせて高速に検索する仕組みが求めら れる、この仕組みにおいて，入力されたデータから(i)

「特徴」を抽出し，(ii)その特徴に基づいてインデクス が生成され,インデクスを基にデータが検索されること が望ましい，検索においては，(iii)インデクス間の類似 度を算出，評価する必要がある。これら(i)〜(iii)の手続 きが,ほほ自動的にストレスのない時間内で処理される ことが理想とされる.

本報において,我々は三次元データ空間に離散的に数 值が定義されたデータ（以下，ボリュームデータ）を対 象として，「特徴」に基づくボリュームデータ間の類似 度を自動算定する仕組みを提案する.ボリュームデータ の特徵には「特異点」および「積分曲線」から構成され る特異点グラフ (CPG ; Critical Point Graph, 以下, CPG) を用いる，CPG の構築手法および特異点，積分曲線は 第 2 章において詳述する.

本報の構成は，以下の通りである．第 2 章において， 提案手法である $\mathrm{CPG}$ を用いた類似度算出手法について 詳述する. 第 3 章では, 四面体を用いたボリュームデー 夕の類似度算定手法を提案する。第 4 章では実験に用い るデータおよび実験方法について述べる。第 5 章では， 得られた結果を考察し，提案手法の有用性に言及する。 最後に，第 6 章において，本報をまとめ，今後の展開に ついて展望を述べる。

\section{2. 特異点グラフを用いた類似度計算手法}

本報において，以下の手続きにより作成される CPG を用いて類似度を算出する手法を「CPG 法」と呼ぶ。

\section{$2.1 \mathrm{CPG}$ の構築}

以下, (1)〜(4)に CPGの構築手法を述べる.

(1)特異点 (CP; Critical Point) の抽出

ボリュームデータから勾配ベクトルを算出し,スカラ 值が定義されている立方体において，勾配ベクトルが 0 となる点を $\mathrm{CP}$ として探索する ${ }^{1)}$. CP 算出過程において， 立方体内の勾配べクトルの補間には，三重線形補間法を 用いた．また，本報では，対象となる格子点の隣接格子 点におけるスカラ值から, 差分近似法を用いて勾配べク トルを算出した． CP の分類は, Helman ら ${ }^{2)} の$ 方法に 従った。

(2)デ一タ境界特異点(BCP; Boundary Critical Point)の抽出 ボリュームデータ内部の CP だけの考虑では, 境界面 上のスカラデータがグラフ構造に反映されないという 問題を生じる. BCP を設定することにより，データ境 界のスカラ值がグラフ構造に反映されるため, より適切 なグラフ構造を構築することができる.ボリュームデー 夕の境界面は二次元の正方格子で構成されているため, BCPは二次元空間における $\mathrm{CP}$ となる. BCPの算出方法, 分類方法は，2.1(1)に従った.

(3)積分曲線の算出

$\mathrm{CP}$ 付近で積分曲線開始点を設定し，積分曲線を算出 する.開始点の設定手法は，小山田らの方法りに従った。 
本報において，ボリュームデータの立方格子間隔を $d$ と定めた場合, 積分曲線開始点は鞍点から固有ベクトル 方向に $0.5 d$ 移動した点の座標を用いた。 また,

積分には, 2 次ルンゲクッタ法を用いた. 積分曲線の終 了条件は, 積分曲線端の積分点が CP もしくは BCP と $0.5 d$ まで接近した場合と定めた.

(4)不要 BCP と不要積分曲線の削除

上記(3)までの処理において，与えられる場によって は, CP 間もしくは CP と BCP 間を接続していない積 分曲線や, どこにも接続していない BCP が存在する. そこで，以下の条件に合う BCP および積分曲線を削除 する.

(1)両端が CP および BCPに接続していない積分曲線

(2)積分曲線に接続していない BCP

(3)特定の CP と鞍点間に 2 本以上の積分曲線が存在する 場合, 最短経路の積分曲線を除くすべての積分曲線

(1)〜 (3)の操作により,グラフ構造構築において, 必要 以上の $\mathrm{BCP}$ および積分曲線を削除する.

\subsection{CPG マッチングアルゴリズム}

CPG 間の位置合わせおよび類似度算出手法を以下に 示す.

\section{(1) CPG 間の位置合わせアルゴリズム}

$\mathrm{CPG}$ を構成する $\mathrm{CP}$ 集合を利用して CPG の正規化を 行うことにより，2 つの CPG 間の位置合わせを行う. CPG の正規化は, 以下の(1)〜(3)過程を経て行われる.

(1)CP 集合の重心を基準とする平行移動

$\mathrm{CP}$ 集合の重心を算出し, データ空間の原点位置に並 行移動する.

(2)CP 集合の主成分分析を用いた回転軸の設定

CP 座標の各成分を用いて分散共分散行列を算出する. 分散共分散行列 $M_{1}$ は以下のように表される.

$$
M_{1}=\left[\begin{array}{lll}
V_{x}^{2} & C_{x y} & C_{x z} \\
C_{y x} & V_{y}^{2} & C_{y z} \\
C_{z x} & C_{z y} & V_{z}^{2}
\end{array}\right]
$$

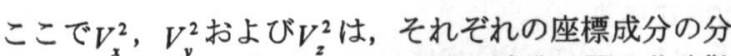
散, $C_{x y}{ }^{x} C_{y z}$ および $C_{z x}$ は 2 つの座標成分の間の共分散 を表す. $M_{1}$ の固有值, 固有ベクトルを算出する. 最大 の固有値に対応する固有ベクトルが CP 集合の第 1 主成 分軸となる. $M_{1}$ を用いて, 以下の行列 $M_{2}$ を算出する.

$$
M_{2}=M_{1}-\lambda\left[\begin{array}{ccc}
v_{x}^{2} & v_{x} v_{y} & v_{x} v_{z} \\
v_{y} v_{x} & v_{y}^{2} & v_{y} v_{z} \\
v_{z} v_{x} & v_{z} v_{y} & v_{z}^{2}
\end{array}\right]
$$

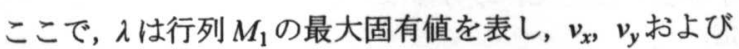
$v_{z}$ は行列 $M_{1}$ の最大固有值に対する固有べクトルの各成 分を表す. この行列 $M_{2}$ の最大固有値に対する固有ベク トルが $\mathrm{CP}$ 集合の第 2 主成分軸である. 第 1 主成分軸を データ空間の $\mathrm{X}$ 軸に, 第 2 主成分軸が $\mathrm{Y}$ 軸に一致する ように回転行列を算出し, CPG を回転させる.

(3)CPG スケールの正規化

CPG 内で用いられる座標系は, ボリュームデータのス カラ值が定義されている格子サイズに依存する.そのた め,解像度がそれぞれ異なるボリュームデータ群から構 築された CPG 間の類似度は単純には比較できない. CPG の大きさを正規化することにより, 解像度が異な るボリュームデータから構築された CPG 間の類似度計
算を可能とする.

尚, CPG の正規化に用いる $\mathrm{CP}$ 集合には, $\mathrm{BCP}$ を含 まないものとした.

\section{$2.3 \mathrm{CPG}$ を用いた類似度算出}

(1)類似度計算手法のためのデータ空間分割

CPG を構成する各 $\mathrm{CP}$ および積分曲線構成点の座標 值を用いて，2 つの CPG に共に外接する直方体を構成 する. 次いで, この外接直方体の $\mathrm{X}$ 軸, $\mathrm{Y}$ 軸および $\mathrm{Z}$ 軸を任意の定数 $n$ で分割する. これらの小領域を, $\mathrm{CPG}$ 間の類似度を計算する際の分割領域とし,類似度計算に 用いる。

\section{(2)類似度算出方法}

CPG 間の各構成 CP およひ積分曲線構成点の位置情 報比較は, ボリュームデータ間のスカラ值勾配を比較す ることと同義である. そこで，2つの CPG 間の各構成 $\mathrm{CP}$ および積分曲線構成点の位置を比較することで類似 度を計算する. 2.3(1)において生成した小領域中で, $\mathrm{CP}$ および積分曲線構成点が存在する小領域を比較するこ とにより類似度を計算する. 以下に $\mathrm{CPG}_{A}$ と $\mathrm{CPG}_{B}$ との 間の類似度 $S$ を算出する計算式を記す。

$$
S=\frac{N_{\text {match }}}{N_{A}+N_{B}-N_{\text {match }}}
$$

ここで, $N_{A}$ および $N_{B}$ は，それぞれの CPG が存在する 小領域の総数を表し, $N_{\text {match }}$ は $2 つ の ~ C P G$ 間で一致した 小領域の数を表す.

\section{3. 四面体マッチング法を用いた類似度算定}

第 2 章で示した CPG 法は, 比較 CP 数が少ない場合, 一つの CP の損により, 正規化パラメータが変化し, 類似度計算結果に影響する. また, 同手法は, 一部分の 領域が重なるデー夕間での類似度算定に対応していな い.この問題に対応するため, 類似した領域を基準に比 較対象のボリュームデータから構築された CPG 間のレ ジストレーション手法を提案する. 本報では, 類似領域 の重ね合わせを行うアルゴリズムとして, 指紋認証分野 で用いられている Triangular Matching algorithm ${ }^{3)}$ をボリ ユームデータに適用範囲を拡張した四面体マッチング アルゴリズム (TM; Tetrahedron Matching , 以下, TM 法) を提案する.

\section{1 四面体マッチングアルゴリズム}

ボリュームデータから抽出された CP をマニューシ ${ }^{4}{ }^{4)}$ として扱い, 4 点の $\mathrm{CP}$ から構成される四面体を基 準にレジストレーションを行うここご，比較する 20 の CPG のうち, CP 数がより少ない CPG を“Refer”，
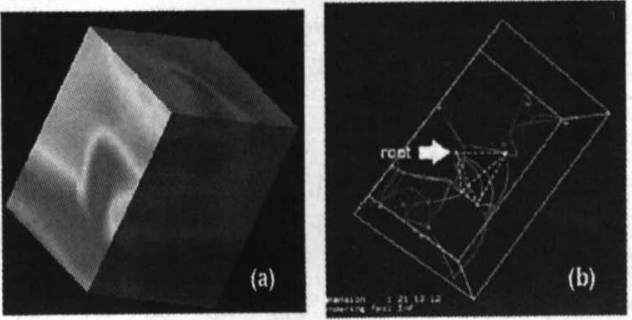

Fig. 1 Data (A) and choosing tetrahedron from CPs

CP 数が多い CPG を“Test”と呼ぶことにする，以下，(1) 〜(3)の手続きを経てマッチングを行う. 


\section{(1)Refer から四面体 $T_{\text {ret }}$ を選択}

Refer に含まれる CP 集合から 1 つの四面体を選択す る方法には，全てのCPから 4 点の CP セットを全て選 択することも考えられるが，構成 CP数が多い場合には， 組み合わせの数が多くなり，計算コストが $O\left(\mathrm{n}^{3}\right)$ で増大 する(nは CP 数). そこで, CPG が積分曲線によって CP 間のつながりを持つことを利用する.積分曲線の計算は， CPのうち鞍点付近から開始される. そこで，四面体を 構成する 4 点のうちの 1 点として鞍点を選択する.この 点を “root” と呼ぶ. root と積分曲線によって接続され る CP 群加ら 3 点を選択し, 四面体を構成する。この場 合の CP 群には， BCP を含まないものとした. Fig.1(b) にCPG から 1 つの四面体を選択するイメージを表す. 3 点の CP 選択は，全ての組み合わせについて，繰り返し 検討する.ここで選択された四面体群を“ $\mathrm{T}_{\mathrm{ref}}$ ”とする. もし, root と接続される $\mathrm{CP}$ 数が 3 点未湮の場合には, 異なる鞍点を rootとして選択し㨁す。

(2)Test からの相似形状四面体探索と $\mathrm{T}_{\text {ref }}$ との対底

$\mathrm{T}_{\text {ref }}$ の選択手法と同様に, Test から四面体 “ $\mathrm{T}_{\text {test }}$ ”を選 択する. 次に, $\mathrm{T}_{\text {ref }}$ と $\mathrm{T}_{\text {test }}$ が相似四面体であるかを判定 する. $\mathrm{T}_{\text {ref }}$ と $\mathrm{T}_{\text {test }}$ を構成する頂点中の root を互いに対応 させる. 他の 3 頂点の対応には, CP の種類(maximum, minimum, saddle)を利用する. $\mathrm{T}_{\text {ref }}$ と $\mathrm{T}_{\text {test }}$ とにおいて, 対応する辺の長さの比 $r_{i}$ を求めることにより，相似の度 合を評価する.

$$
r_{i}=\frac{l r_{i}}{l t_{i}} \quad\{i=0, \ldots, 5\}
$$

ここで，iは2つの四面体間で対応する辺の識別子を表 $L, l r_{i}$ は $\mathrm{T}_{\text {ref }}, l t_{i}$ は $\mathrm{T}_{\text {test }}$ の $i$ 边の長さを表す. 2 つの四 面体間の相似度合が高い場合は，6つの辺の比 $\boldsymbol{r}$ はほほ 一致するが，相似性が低い場合は，その比にばらつきが 生じる.このばらつきを評価するため, 次の変数 $c_{i j}$ を 計算する.

$$
c_{y}=\frac{r_{j}}{r_{i}} \quad\{i, j=0, \ldots, 5\}
$$

これら 36 個の変数がすべて(6)式を満たす場合，2つの 四面体 $\mathrm{T}_{\mathrm{ref}}$ と $\mathrm{T}_{\text {test }}$ は相似関係にあると判定する.

$$
0.95<c_{i j}<1.05 \quad\{i, j=0, \ldots, 5\}
$$

\section{（3）四面体を基準としたCPG 間のレジストレーションおよひ 類似度計算}

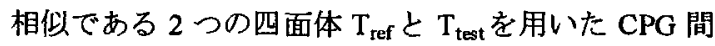
のレジストレーションおよび類似度計算処理の過程を 以下に示す.

(1)root をデータ座標系の原点に平行移動

(2)四面体を基準とした CPG のスケーリング

(3)面体を基準とした CPG の回転操作

(4)CPG 間の類似度計算

類似度計算は，CP 数が少ない Refer を基準とする。 Refer の CP 群， BCP おょひ積分曲線構成点の座標值を 用いて，Referに外接する直方体を形成し，その外接直 方体の X 軸，Y 軸および $\mathrm{Z}$ 軸を一定数 $\mathrm{n}$ で分割するこ とにより，類似度計算に用いる小領域を作成する. 類似 度計算は，第 2 章に示した方法と同様である.

\section{4. 実験}

計算機環境には, CPU : PentiumM 1.1GHz, Memory：
760MB，OS：WindowsXP を用いた.

Table1 Volume data sets

\begin{tabular}{c|c|c}
\hline Name & Attribute & Resolution \\
\hline A & Scalar volume data (basis) & $25 \times 25 \times 25$ \\
\hline B & $90^{\circ}$ rotation around X-axis & $25 \times 25 \times 25$ \\
C & $90^{\circ}$ rotation around Y-axis & $25 \times 25 \times 25$ \\
D & $90^{\circ}$ rotation around Z-axis & $25 \times 25 \times 25$ \\
\hline E,F & a part of data (A) & $13 \times 19 \times 19$ \\
\hline G & mirror data of data (A) & $25 \times 25 \times 25$ \\
\hline H & data (A) minus const. value & $25 \times 25 \times 25$ \\
\hline
\end{tabular}

類似度計算および比較に用いたボリュームデー夕を Table 1 および Fig.1(a)に示す（データは, AVS Express® に内蔵される wind.fld $の \mathrm{x}$ 成分值の一部である.)。 $\operatorname{Data}(\mathrm{A}) \sim \operatorname{Data}(\mathrm{F})$ 間で総当り組み合わせにより，ボリュ 一ムデータ間の類似度を算定した. また, 類似度計算に 用いる外接直方体の分割数は 32 とした.

\section{5.結果と考察}

Fig.2(a)およびFig.2(b)にそれぞれ，CPG 法および TM 法 を用いて算定した Data(A)〜Data(G)間の類似度を示す。 また Table2 と Table3 は，それぞれの類似度計算に要す る計算時間 $(\mathrm{ms})$ を示す。計算時間は，10 回平均値で ある。

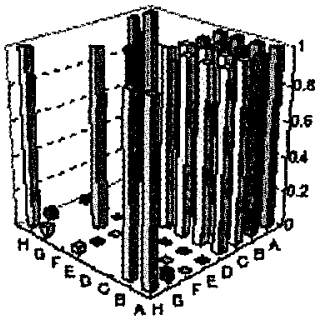

(a) CPG method

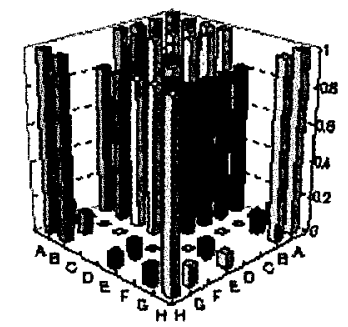

(b) TM method
Fig. 2 Results of similarity measure

Table 2 Computation time when using CPG method

\begin{tabular}{c|cccccc}
\hline Name & A & B & C & D & E & F \\
\hline A & 3.7 & 2.9 & 2.6 & 3.5 & 3.3 & 3.7 \\
B & 2.9 & 3.8 & 3.4 & 4 & 3.6 & 3.4 \\
C & 2.6 & 3.4 & 3.6 & 3.6 & 2.8 & 3 \\
D & 3.5 & 4 & 3.6 & 4.2 & 3 & 2.9 \\
E & 3.3 & 3.6 & 2.8 & 3 & 2.5 & 2.7 \\
F & 3.7 & 3.4 & 3 & 2.9 & 2.7 & 2 \\
\hline
\end{tabular}

[ms]

\section{1 データ回転による類似度の変化}

Data(A)〜Data(D)間の類似度を比較した結果（Fig.2(a) および(b))，CPG 法，TM法ともに，類似度計算にデ一 夕回転変形の影響を受けないことが分かり,両手法とも に意図通りの動作をしていることを確認した。 
Table 3 Computation time when using TM method

\begin{tabular}{c|cccccc}
\hline Name & A & B & C & D & E & F \\
\hline A & 18.5 & 47 & 14.1 & 14.7 & 48.3 & 0.1 \\
B & 47 & 15 & 64 & 59.9 & 48.5 & 0.1 \\
C & 14.1 & 64 & 17.4 & 14.2 & 46 & 0.1 \\
D & 14.7 & 59.9 & 14.2 & 15.6 & 48.5 & 0.1 \\
E & 48.3 & 48.5 & 46 & 48.5 & 8.2 & 0.1 \\
F & 0.1 & 0.1 & 0.1 & 0.1 & 0.1 & 0.1 \\
\hline
\end{tabular}

[ms]

\section{2 領域を切り出したボリュームデータとの類似度計算}

$\operatorname{Data}(\mathrm{A})$ と Data(F), または, Data(A)と Data(G)間の類似 度は, CPG 法を用いた場合（Fig.2(a)）では，どちらの データ間においても, 非常に低い類似度を算定した.こ れは, CPG 法が, 比較するデータ領域で過不足なく CPG が抽出されていることを前提とした手法であることに 原因がある。一方, TM 法 (Fig.2(b)) では, Data(A)と $\operatorname{Data}(\mathrm{F})$ 間の類似度が計算され, 比較的高い数値を示し た。しかしながら, Data(A)と Data(G)間の類似度は算定 されなかった. これは, TM 法における四面体の対応付 け方法に起因するものである.Fig.3に Data(F)と Data(G) から抽出された CPG を示す.

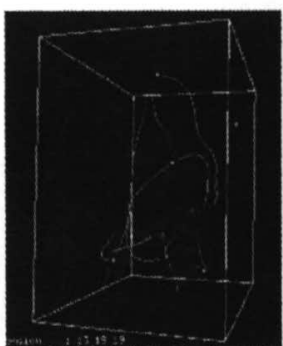

(a) $\operatorname{Data}(F)$

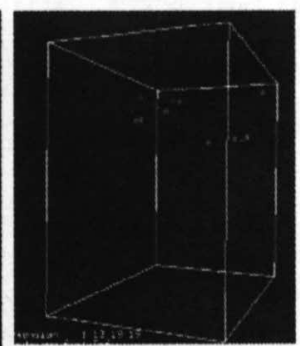

(b) $\operatorname{Data}(G)$
Fig. 3 Extracted CPG from Data $(F)$ and Data $(G)$

TM 法における四面体の対応付けにおいては, 積分曲 線により互いに接続されている $\mathrm{CP}$ 数が 3 以上ある鞍点 の存在が必要である. Data(F)はこの場合に相当する。 しかしながら $\operatorname{Data}(\mathrm{G})$ のように, 接続 $\mathrm{CP}$ 数が 3 以上あ る鞍点が存在しない場合は, TM 法によるレジストレー ションが不可能となる. 以上の結果, TM 法においては, 接続 CP 数が 3 以上ある鞍点が必要であり，適用範囲の 限界を有している.

5.3 鏡像データとの類似度 : Data(A)と Data (G) の比 較

$\operatorname{Data}(\mathrm{A})$ と $(\mathrm{H})$ は鏡像関係にあり，それぞれから得ら れる CPG 間にも鏡像関係が残る. そのため, CPG 法 では，類似度が完全に0にはならない，一方，TM 法を 用いた場合, $\operatorname{Data}(\mathrm{A})$ と (H) 間で類似の四面体を抽出 した. しかしながら， TM 法は鏡像データの特定に対応 していないことから, 類似度は 1 にならない.

\section{4 類似度計算時間の比較}

Table 3 に TM 法による類似度計算時間を示す.まず, $\operatorname{Data}(\mathrm{F})$ と他のデータとの間で類似度を計算する場合, 他の場合と比べて突出して計算時間が短い. Fig.3(b)に 記されている Data(F)と他のデータとの間の類似度は, 全て 0.0 になっている. これは, Data(F)の CPG から TM
法に必要な四面体を構成する鞍点が存在しないことに より, 類似度計算が打ち切られたことを表している.

同一データ間での類似度計算時間は, 四面体を構成で きるデータ間の類似度計算時間においては, 他と比較し て早い. TM 法の計算過程は, 大きく 2 つのステップに 分けられており，第一ステップでは，互いに相似な四面 体を全て探索する. 第二ステップでは, 選択された四面 体を基準にレジストレーションを行い, 類似度を計算す る. 第二ステップでは, 計算中に類似度が 0.99 以上に なった場合，処理を終了するように定めている. そのた め, 同一データ間の類似度計算は, 第二ステップにかか る時間が短くなり,全体の計算時間も短くなったと考え られる. Table 4 に Data(A)同士間, Data(A)と Data(B)間 の類似度計算に伴う第一ステップおよび第二ステップ の計算時間を記す。

\begin{tabular}{|c|c|c|}
\hline Data & Step1 & Step2 \\
\hline $\begin{array}{l}A-A \\
A-B \\
A-E\end{array}$ & $\begin{array}{l}2.0 \\
2.0 \\
3.8\end{array}$ & $\begin{array}{l}13.0 \\
38.0 \\
91.2\end{array}$ \\
\hline
\end{tabular}

\section{6. まとめ}

スカラボリュームデータから特徴を抽出し, 類似度を 算定する手法として, CPG 法および TM 法を提案した. CPG 法は, 同一解像度のデータ同士の比較を想定した ものであり, TM 法は, 解像度によらない方法である. CPG 法では, 同一解像度のデータ同士の比較において 良好な類似度算出結果を得た。.また, TM 法では, 一部 分の類似度を算定できることを示した.

TM 法は, レジストレーションの鍵となる root 鞍点の 存在が必要であり,これが存在しない場合には, 類似度 を算出することが出来ないという問題点がある.このよ うな問題では, そもそも CP 数が少ない場合が考えられ る、そのような場合には, CPG 法を用いることによっ ても現実的な計算時間で目的を達するものと考えられ る.このような場合に対応した検索システムの開発が, 今後の課題となる.

\section{謝辞}

本研究の一部は, 文部科学省科学研究費補助金 (若手研 究者(B)17700293）の支援を受けて実施されたものであ る.

\section{参 考 文 献}

1）小山田耕二, 土井章男, 千葉則茂, 三中西信治, “四 面体格子を用いた渦の可視化一数值流体シミュレーシ ヨンへの適用一”, 電子情報通信学会論文誌 D-II, Vol.J79-D-II, No.11, pp.1871-1878

2) Helman, J.L., Hesselink, L., "Visualization of Vector Field Topology in Fluid Flows", IEEE Computer Graphics and Applications, Vol.11, No.3 (1991), pp.36-44

3) Kovacs-Vajna, Z.M., "A fingerprint verification system based on triangular matching and dynamic time warping", IEEE Transaction on Pattern Analysis and Machine Intelligence, Vol.22, No.11 (2000), pp.1266-1276 